\title{
Educational mentoring an effective tool for social and pedagogical support in developing hardiness
}

\author{
Elena Bayer* and Anna Kryuchkova \\ Don State Technical University, 344000, Rostov-on-Don, Russian Federation
}

\begin{abstract}
The article focuses on the importance of educational mentoring for older adolescent orphans that involves community-minded non-profit organizations. The authors have sufficiently substantiated and developed a technology of educational mentoring for orphans of school leaving age to be applied in centres for helping childreninvolving representatives of community-minded non-profit organizations in order to form the orphans' skills and competencies necessary for living on their own, increase their level of hardiness and actualize the value and moral contexts. The effectiveness of the developed technology is ensured by the creation of such a pedagogical space in which, in the interaction of employees of the center for helping children and mentors-volunteers of a non-profit organization, a huge impact is made on the indicators of the formation of personal characteristics of the resilience of graduates and, in the future, on the results of their social adaptation and integration in society. The author comes to the conclusion that the system of pedagogical mentoring of orphans allows to increase the level of their social adaptation. The indicators of this technology are the spiritual and moral values inherent in the Russian family, and the mentoring technology is a pedagogical tool for the formation of model characteristics of a resilient graduate in orphans.
\end{abstract}

\section{Introduction}

Today, the asocial behaviour of orphans graduated from orphanages is one of the central current challengesfacingRussia and society as a whole.

To a greater extent, such personality traits of orphans as dependency, the difficulties in self-sustaining life, deviations, latent or explicit aggression are the result of living in an orphanage and alienation from the family. At the same time, it is important to emphasize that social orphans often lack a stable understanding of family mechanisms, mutual commitment of family members to each other's problems and experiences, social responsibility, the value of living together and other properties necessary for effective socialization.

Lack of general awareness of social roles, inability to feel the father and mother role models due to their stay in the centre for helping children can cause social maladjustment and loss of motivation for a socially responsible lifestyle in orphans leaving school.

In this regard, it is necessary to note the vital role of pedagogical science in providing the mechanism of educational mentoring as one of the most powerful tools in the system of

* Corresponding author: elenabaier@list.ru 
supportingschool leavers in a centre for helping children in order to create a socially adaptable, hardy personality. In our opinion, it is possible to achieve this goal under the condition of close interaction of trained and motivated mentors, orphanage specialists and an expert organization that trains mentors and supervises them.

It is also very relevant in this research to focus on the essence of the very concept of "educational mentoring". Recently, educational mentoring has been one of the most significant and developed tools for psychological and pedagogical support and development of an orphaned adolescent personality. Since we will be discussing the asocial environment from which the children got intoorphanages, and the difficult living conditions of these children in children's homes, in this context, the most challenging is the very possibility of future upbringing, social rehabilitation, adaptation and development of hardiness in adolescents [1] and sustainable motivation to follow simple everyday rules for successful self-realization in society. Thus, educational mentoring has the goal of socializing adolescentorphans, especially those who have been treacherously abandoned by people who used to be significant for them; orphans, for whom everything connected with the world of adults is associated with insecurity and danger.

The purpose of the study is to substantiate and build the technology of educational mentoring for orphans of school leaving age in centres for helping children in collaboration with representatives of community-minded non-profit organizations in order to developorphaned adolescents' skills and competencies necessary for living on their own, to increase their level of hardiness and actualize ethical and moral values for them.

\section{Materials and Methods}

We used the following methods in our study:

- theoretical: analysis of psychological and pedagogical literature on the issues under study;

- method of socio-pedagogical research based on a substantive analysis of the relationship and interaction of socialization agents of orphans, identifying contradictions in their interaction, ways to resolve emerging problems depending on the conditions for organizing the mentoring process.

The method of analyzing legal acts and other documents regulating the activities of state support for orphans and children left without parental care have played an important methodological role in the study.

\section{Results}

We have constructed a model of educational mentoring for orphans based on the works of Soviet and Russian authors, as well as on the Russian state policy in child protectionand official documents including the "Strategy for the Development of Education in the Russian Federation until 2025" and the Decree of the Government of the Russian Federation of May 19, 2009 No. 432 "On the Temporary Transfer of Children fromOrganizations for Orphans and Children Left without Parental Care toFamilies of Citizens Permanently Residing on the Territory of the Russian Federation" (Figure 1). 


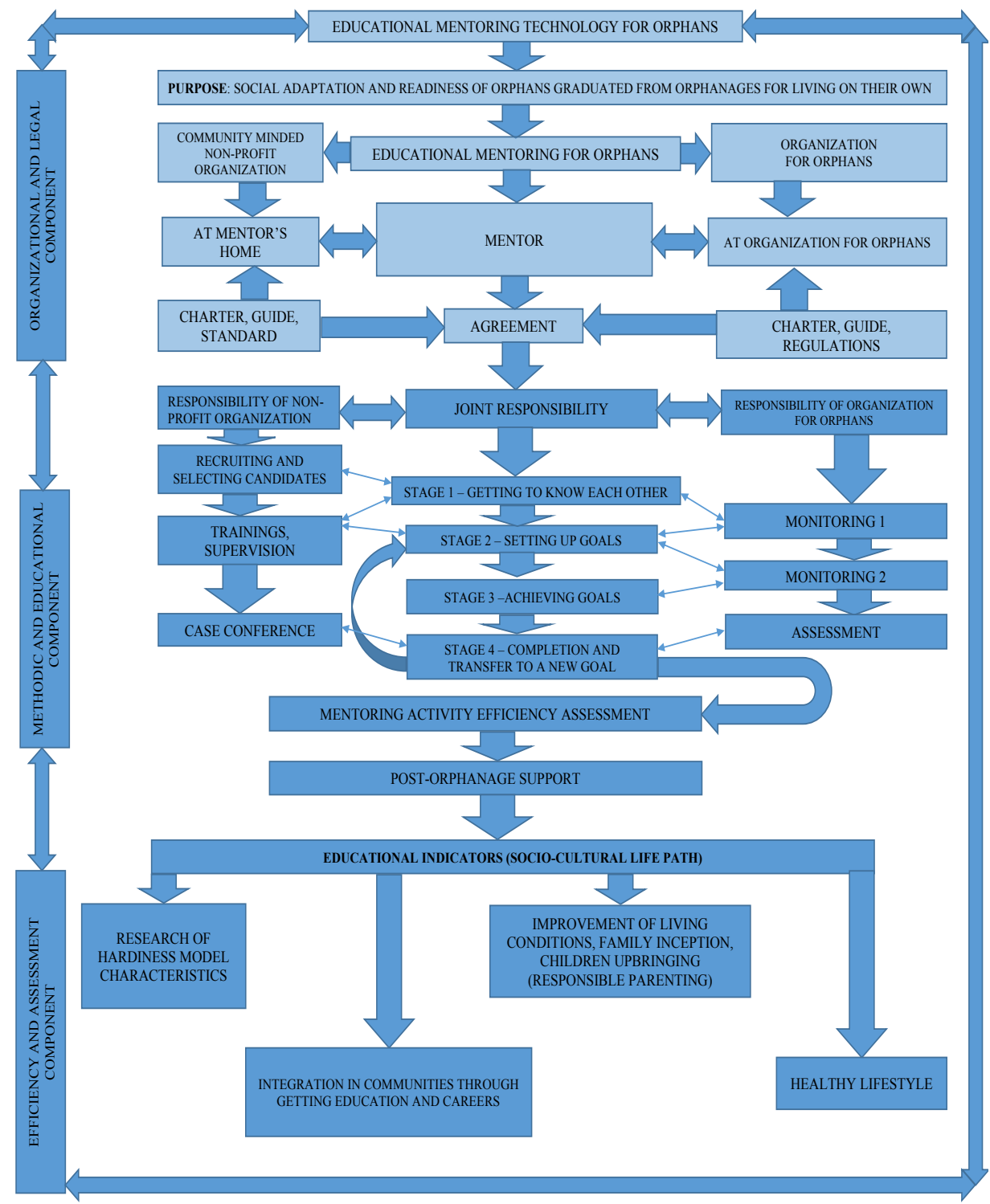

Fig. 1. Modelof educational mentoring for orphans

The fundamental basis for implementing the developed model is a tripartite close cooperation between: employees of child care institutions, specialists of a communityminded non-profit organization and volunteer mentors. The leading goal of organizing joint cooperation is to maximize the use of possible influences on social adaptation and the general development of an orphan teenager. At the same time, volunteer mentors act as a model familywhere a teenager learns simple household and life skills: making the right decisions, learning self-service, gaining physical, intellectual, cultural, psycho-emotional and moral self-improvement.

Organizations for orphans which remain the only legal representatives of orphan teenagers provide their needs, constantly monitor the adolescents' living condition and 
participate in the final examination and consultation at the end of the mentoring program in order to determine the graduates' readiness for living on their own.

At the same time, a community-minded non-profit organization plays an important role in the context of providing the necessary training for mentors, supervising their activities, organizing a joint consultation in order to determine the graduate's readiness for an independent life. Assuredly, the readiness of a school leaver for living on their own is determined by the correspondence of the criteria (educational indicators) incorporated in the technology as an efficiency and assessment component to the set values and goals.

At the stage preceding the use of the above-mentioned psychological and pedagogical approaches, it is necessary to devote sufficient time to a thorough qualitative study of all the participants of the mentoring process.

In our opinion, it is relevant to dwell upon a more detailed consideration of the main stages of the model's implementation. At the first stage of the pedagogical experiment, the mentors were selected, the experimental and control groups of older adolescent orphans were formed.

At the ascertaining stage of the pedagogical experiment, the level of readiness of the adolescents for post-orphanage socialization was studied. 20 adolescents of school leaving age from orphanages located in the Rostov region (the main group) and 40 adolescents from blood families (the control group) took part in the research. According to the findings of the study theadolescentsfrom orphanages located in the Rostov region have a low level of readiness for post-orphanage socialization. These problems require timely developmentalsupport.

We also developed a program based on the results of testing adolescents to prepare orphans of school leaving age for post-orphanage socialization - "Program for school leavers from social support organizations "My soft skills for the future". The formative work was carried out over two years from 2019 to 2021.

The results of the control testing of adolescents have shown that by the end of the second year of training, the adolescents from orphanages have gained a stable improvement in the general level of hardiness, involvement, social skills and the level of social adaptation. The level of intellectual abilities in terms of emotional and social intelligence has significantly increased, and steady transformations in the structure of value orientations have been noticed.In general, we can state an increase in the level of the orphaned school leavers' readiness for post-orphanage socialization.

The results obtained demonstrate the relevance and effectiveness of the use of the mentoring technology in the practice of preparing school leavers for postorphanagesocialization. "Program for school leavers from social support organizations "My softskills for the future" has been successfully tested and its effectiveness has been confirmed.

\section{Discussion}

To date, researches by specialists, psychologists, educators and teachers show that adolescents from organizations for orphans and children left without parental care differ significantly from teenagers living in a family in the terms of mental and physical development.

In Russia, the issues of pedagogical mentoring were first raised by S.T. Shatsky (18781934) whose research subject was the influence of the microenvironment conditions surrounding children on their socialization [2].

A well-known researcher in the field of education and upbringing V.S. Basyuk argues that it is possible to form a children's cognitive and value-emotional spheredue to their transformative activities [3]. 
In our opinion, M.V. Boguslavsky agrees with S.T. Shatsky that a child is a bearer of the total environmental impacts including the environment norms, traditions and customs passed down from generation to generation [4]. Only the synthesis of moral and mental, volitional and emotional education allows us to productively solve the questions posed by life. In fact, this is a mentoring aspect.

Particularly noteworthy is the position of G. Lewis who considers the concept of "mentoring" as a system of relationships and a series of processes when one person offers individualized assistance, guidance, advice and support to another [5]. G. Lewis defines a mentor as a person with a certain experience and knowledge, a high level of communication, striving to help thementee to acquire the necessary and sufficient experience to master the profession. The roles that a mentor should be able to perform are the following: a guide, a sourceof knowledge, a teacher, a friend, a counsellor, an assistant, an expert, an instructor, acatalyst, a role model, a stimulator, a sourceof energy, a time manager, a diagnostician, a goal setter, asupervisor, a planner, a problem solver.

Due to the different problems of orphanages in Europe and Russia, the focus of contemporary Western research differs significantly. In particular, much attention is paid to a short-term stay of children in organizations (a period of three to six months before they are transferred to a foster family), while there is practically no research on a long-term stay of children which is typical for children in Russia.

So, R. Johnson in 2006 conducted a comparative analysis of 27 research papers on the issues of developing children brought up in the institutional environment [6]. Seventeen papers from his review were devoted to assessing the behavioural and social adaptation problems of these children, and 16 of them demonstrated evidence that the identified problems do exist. They pointed to antisocial attitudes, weak connections with the environment of peers and adults.

In addition, some researches carried out in European institutions confirmed a more stereotypical behaviour of children raised in institutional careorganizations when compared with family children - theyoung children showed a decrease in social skills after 6 months of stay in such an institution. The consequence of unsuccessful attempts to communicate with the educators and staff for children is uncommunicativeness, and their manifestation of initiative in communication is becoming increasingly rare [7;8].At the same time, children placed in small family-type orphanages with several permanent caregivers are less susceptible to these changes.

The analysis of foreign and Russian experience shows that mentoring is actively used all over the world $[9 ; 10]$, and the institution of mentoring itself is constantly developing and improving in accordance with the needs of the time and a particular state.

\section{Conclusions}

1. The technology of educational mentoring of orphans involving socially oriented non-profit organizations is aimed at achieving the main goal of increasing preparedness of school leavers from centres for helping children forliving on their own in society. The effectiveness of this technology is ensured by creating such a pedagogical space where the interaction of the employees of the centre for helping children and volunteer mentors of the non-profit organization contributes to achieving a colossal effect on the orphans' personal characteristics indicators of hardiness and, in the future, on the results of their social adaptation and integration in society.

2. The algorithm for developing hardiness presupposes a stage of self-affirmation associated with relieving stress and reaching a new level of self-realization and actualization of the value aspect contributing to the effective socialization of an orphanage graduate in society [11- 15]. 
3. The presented technology of educational mentoring by introducing orphans into family relations and placing them in a situation of empirical perception of family functioning and family relations on the example of the role family model of mentors is represented by interrelated components reflecting the specific features of the activity of a volunteer mentor. The components of the model show the mentor's readiness to transfer their knowledge, experience, and individually influence to the adolescent.

4. The system of educational mentoring for orphans makes it possible to increase the level of their social adaptation. The ethical and moral values traditionally inherent in the Russian family act as indicators of thementoring technology that serves as a pedagogical tool for developing model characteristics of hardiness in adolescent orphans.

5. The results of the work done enabled us to assess the potential possibilities of the social partnership concept "Mentor of a community-minded non-profit organization - a social organization for orphans" in solving the problems of supporting orphans based onthe mentoring technology. This showed the feasibility of continuing the work begun, promising possibilities of the proposed solution and an extensive social impact.

\section{References}

1. E.A. Bayer, S. Avakov, N.A. Grigoryan, R.L. Arutyunyan, SHS Web of Conferences 70, 01003 (2019). The conference proceedings: Trends in the development of psychopedagogical education in the conditions of transitional society, Rostov-on-Don, Don State Technical University. DOI: 10.1051/shsconf/20197001003

2. S.T. Shatsky, Pedagogical Essays. In 4 volume, Moscow 4 (1965).

3. V.S. Basyuk, Psychological and Pedagogical Support as a Compensating Condition for the State of Mental Deprivation in Orphans, Moscow (2007).

4. M.V. Boguslavsky, Ascetics and Reformers of Russian Education (Moscow, 2005).

5. G. Lewis, The Mentoring Manager: Strategies for Fostering Talent and Spreading Knowledge (New Jersey, Financial Times, Prentice Hall; 2nd edition, 1999). ISBN: 9780273623441

6. R. Johnson, K.D. Browne, C.E. Hamilton-Giachritsis, Trauma Violence and Abuse 7 (1), 1-26 (2006). DOI: $10.1177 / 1524838005283696$

7. C.A. Nelson $3^{\text {rd }}$ C.H. Zeanah, N.A. Fox, P.J. Marshall, A.T. Smyke, D. Guthrie, Science 318 (5858), 1937-40 (2007). DOI: 10.1126/science.1143921.

8. M.H. Ijzendoorn, Je. Palacios, E.S. Sonuga-Barke, M.R. Gunnar, P. Vorria, R.B. McCall, L. LeMare, M.J. Bakermans-Kranenburg, N.A. Dobrova-Krol F. Juffer, Children in Institutional Care: Delayed Development and Resilience, Monographs of the Society for Research in Child Development 76 (4), 8-30 (2011). DOI: 10.1111/j.15405834.2011.00626.x

9. N. Tottenham, T.A. Hare, A. Millner, T. Gilhooly, J.D. Zevin, B.J. Casey, Dev Sci. 2011 Mar; 14 (2), 190-204 (2011). DOI: 10.1111/j.1467-7687.2010.00971.

10. K.D. Browne, C. Hamilton-Giachritsis, R. Johnson, S. Chou, M. Ostegren, I. Leth, H. Agathonos-Georgopoulou, M. Anaut, M. Herczog, M. Keller-Hamela, A. Klimackova, V. Stan, S. Zeytinoglu, Adoption \& Fostering 29 (4), 23-33, (2005).

11. S.R. Maddi, Hardiness: Turning Stressful Circumstances into Resilient Growth. Series: Springer briefs in psychology (New York-London, 2013). DOI: 10.1007/978-94-0075222-1_6

12. S.R. Maddi, Consulting Psychology Journal 54, 175-185 (2002). DOI: 10.1037/10614087.54.3.173 
13. S.R. Maddi, M.D. Matthews, D.R. Kelly, Military Psychology 29 (5), 355-358 (2017). DOI: $10.1037 / \mathrm{mil} 0000145$

14. S.R. Maddi, L.M. Erwin, C.L. Carmody, B.J. Villarreal, M. White, K.K. Gundersen, The Journal of Positive Psychology 8 (2), 128-134 (2013). DOI: 10.1080/17439760.2012.758306

15. S.R. Maddi, R.H. Harvey, D.M. Khoshaba, M. Fazel, and N. Resurreccion, Journal of Positive Psychology 4, 566-577 (2009). DOI: 10.1080/17439760903157133 